\title{
Maternal complications in eclampsia and pre-eclampsia: an institutional study
}

\author{
Harsha Konnur*1, Shilpa Modi² \\ ${ }^{1}$ Department of Obstetrics and Gynecology, ESI Medical College, Kalaburagi, Karnataka, India \\ ${ }^{2}$ Department of Obstetrics and Gynaecology, KBNIMS, Kalaburagi, Karnataka, India
}

Received: 25 September 2018

Accepted: 22 October 2018

\author{
*Correspondence: \\ Dr. Harsha Konnur, \\ E-mail: harsha.ramdurg@gmail.com
}

Copyright: (c) the author(s), publisher and licensee Medip Academy. This is an open-access article distributed under the terms of the Creative Commons Attribution Non-Commercial License, which permits unrestricted non-commercial use, distribution, and reproduction in any medium, provided the original work is properly cited.

\begin{abstract}
Background: Preeclampsia and eclampsia are associated with higher rates of maternal, fetal, and infant mortality, and severe morbidity, especially in cases of severe preeclampsia, eclampsia, and HELLP syndrome. The aim of the study was to determine maternal outcomes in pregnant women with severe preeclampsia and eclampsia.

Methods: This was a retrospective descriptive study carried out at Vaatsalya Life Hospital, a tertiary hospital in Kalaburagi, Karnataka from January 2016 to June 2018. All patients admitted with preeclampsia and eclampsia were analysed for the maternal complications.

Results: A total of 100 deliveries were conducted during the study period of which 71 cases were severe preeclampsia and eclampsia. Most of the patients were primi parous with mean age of 26.5 years. There were 32 cases of severe preeclampsia and 39 cases of eclampsia. The most common complication was HELLP syndrome in 6 cases ( 2 with ARF). There was one case of maternal mortality.

Conclusions: We conclude that severe preeclampsia and eclampsia are associated with higher rates of maternal severe morbidity and that these two factors still remain the major contributors to maternal morbidity and mortality.
\end{abstract}

Keywords: ARDS, eclampsia, HELLP, Renal failure Pre-eclampsia

\section{INTRODUCTION}

Severe preeclampsia/eclampsia has grave consequences for both maternal and neonatal health, associated with 50,000-100,000 annual deaths globally, as well as serious fetal and neonatal morbidity and mortality. ${ }^{1,2}$ These disorders of pregnancy have a predominance in low- and middle-income countries. ${ }^{3}$ The biggest killers of pregnant women being hemorrhage, hypertensive disorders, and sepsis. ${ }^{4}$ Hypertensive disorders also indirectly contribute to maternal deaths by being a common risk associated with postpartum hemorrhage. ${ }^{5}$

Preeclampsia complications do arise in about $3 \%$ of pregnancies, and all hypertensive disorders affect about $5-10 \%$ of pregnancies. Hypertensive disorders are associated with higher rates of maternal, fetal, and infant mortality, and severe morbidity, especially in cases of severe preeclampsia, eclampsia, and haemolysis, elevated liver enzymes, and low platelets syndrome. ${ }^{6,7}$ Globally, preeclampsia and eclampsia account for 10-15\% of maternal deaths. A majority of deaths in developing countries result from eclampsia, while in developed countries, complications of preeclampsia are more often the cause. ${ }^{8}$ The present retrospective, descriptive study was undertaken to determine maternal complications in severe preeclamptic and eclamptic women in Vaatsalya Life hospital, Kalaburagi, Karnataka.

\section{METHODS}

This was a retrospective descriptive cohort study carried out at Vaatsalya Life hospital, a tertiary care hospital from 2016 January to 2018 June. It is a tertiary hospital 
with referral for high risk pregnancies. Data were obtained from the Case files, labour ward records, Operation theatre notes, discharge summaries and intensive care unit (ICU) of patients who had a diagnosis of severe preeclampsia or eclampsia.

\section{Inclusion criteria}

- Patients of severe preeclampsia and eclampsia.

- Severe preeclampsia was diagnosed in those patients with high blood pressure (systolic of $>$ /= 160 and diastolic $\geq 110 \mathrm{mmHg}$ ) and either severe headaches, epigastric pain, or deranged biochemical/ hematological blood indices.

- Eclampsia was diagnosed in women who had a grand mal seizure with features of preeclampsia and no previous history of a seizure disorder such as epilepsy.

\section{Exclusion criteria}

- Women with chronic hypertension, renal failure, epilepsy and other medical illness unrelated to pregnancy.

Statistics in the form of mean, median and standard deviation of the data was analysed.

\section{RESULTS}

There were 100 deliveries at the institution during the period January 1, 2016, to December 31, 2016. There were 71 cases of severe preeclampsia/eclampsia. The incidence of severe preeclampsia/eclampsia was $71 \%$. The mean age was 26.5 years $(\mathrm{SD} \pm 8.1)$ (Table 1) and the mean parity was $1.0(\mathrm{SD} \pm 1.0)$ (Table 2 ) for the studied group of patients.

Table 1: Age distribution of the patients.

\begin{tabular}{|lll|}
\hline Age (in years) & Number & Percentage \\
\hline$<19$ & 4 & 5.6 \\
\hline $19-24$ & 28 & 39.4 \\
\hline $25-30$ & 29 & 40.8 \\
\hline$>30$ & 10 & 14.04 \\
\hline
\end{tabular}

Table 2: Parity of patients.

\begin{tabular}{|lll|}
\hline Parity & Number & Percentage \\
\hline Primi & 50 & 70.4 \\
\hline Multi & 21 & 29.6 \\
\hline
\end{tabular}

The mean systolic blood pressure was $168(\mathrm{SD} \pm 16)$ and the mean diastolic blood pressure was 109 (SD \pm 18 ). About $68 \%$ of the cases had a proteinuria of $\geq++$.

Being purely referral centre, all the cases were unbooked. The cases were predominantly of severe preeclampsia 32 cases $(45 \%)$ and 39 cases $(55 \% \%)$ were eclamptic. 47 patients $(66.2 \%)$ presented preterm while 24 patients $(33.8 \%)$ came post 37 weeks of gestation (Table 3 ).

Table 3: Gestational age at presentation.

\begin{tabular}{|lll|}
\hline Gestational age (in weeks) & Number & Percentage \\
\hline $28-34$ & 17 & 23.94 \\
\hline $34-37$ & 30 & 42.25 \\
\hline$>37$ & 24 & 33.80 \\
\hline
\end{tabular}

Most of the cases were delivered by non-instrumental vaginal delivery in 28 cases $(39.4 \%)$, vacuum assisted delivery in 15 cases $(21.1 \%)$, Forceps delivery in 2 cases $(2.8 \%)$ and caesarean section in 26 cases $(36.6 \%)$ Table $4)$.

Table 4: Mode of delivery.

\begin{tabular}{|lll|}
\hline Mode of delivery & Number & Percentage \\
\hline Vaginal (non-instrumental) & 28 & 39.4 \\
\hline Forceps delivery & 02 & 2.8 \\
\hline Vacuum assisted delivery & 15 & 21.1 \\
\hline Caesarean Section & 26 & 36.6 \\
\hline
\end{tabular}

The complications included HELLP syndrome 4 cases, HELLP syndrome with ARF in 2 case $(2.8 \%)$, Placental abruption in 3 cases (4.2\%), ARF in 3 cases (4.32\%), PRES in 2 cases $(2.8 \%)$ ), ARDS in 2 cases $(2.8 \%)$ and DIC in one case $(1.4 \%)$. There was 1 maternal mortality $(1.4 \%)$ (Table 5).

Table 5: Maternal complications.

\begin{tabular}{|lll|}
\hline Complications & Number & Percentage \\
\hline HELLP & 04 & 5.6 \\
\hline HELLP with ARF & 02 & 2.8 \\
\hline Placental abruption & 03 & 4.2 \\
\hline DIC & 01 & 1.4 \\
\hline ARDS & 02 & 2.8 \\
\hline ARF & 03 & 4.2 \\
\hline PRES & 02 & 2.8 \\
\hline Maternal deaths & 01 & 1.4 \\
\hline
\end{tabular}

Other than the cases of acute renal failure who received levitracetam, rest of the patients received magnesium sulphate according to Pritchard regimen for the prevention and treatment of eclamptic seizures. All the cases were admitted to ICU.

The complications were accordingly managed in consultation with the intensivist and critical team doctors.

\section{DISCUSSION}

Vaatsalya Life hospital is a tertiary referral hospital for high risk pregnancies and hence an inherent referral bias leading to high incidence of pre-eclampsia and eclampsia. All the cases in the study were unbooked referred cases. The patients in present study presented with gross 
disease, most of the time with proteinuria $(\geq++)$, mean systolic blood pressure of 168 (SD \pm 27 ), mean diastolic blood pressure of 113 (SD \pm 18 ), or with eclampsia $(21.5 \%)$. These were mostly very sick patients. At our hospital early onset preeclampsia constituted $23.94 \%$ of cases while in the developed world early onset preeclampsia represents $10 \%$ of preeclamptic cases. The predominance of early onset preeclampsia or late onset preeclampsia has huge geographical differences. ${ }^{9,10}$

Maternal complications of severe preeclampsia/eclampsia can be serious, leading to maternal, fetal, and neonatal morbidity and mortality. These include HELLP syndrome, disseminated intravascular coagulopathy and acute renal failure. ${ }^{11,12}$ Severe preeclampsia was found to be associated with an 8.7-fold risk of composite maternal complication. ${ }^{13}$

The risk of a woman in the developing world dying from a maternal-related cause is 33 times higher than a woman in the developed world. ${ }^{14}$

Maternal mortality results from cerebral hemorrhage, pulmonary edema, acute renal failure, hepatic rupture, or DIC. ${ }^{15,16}$ Long-term effects may include chronic renal failure, cardiovascular disease, or cortical blindness. ${ }^{17}$ In present study the complications included HELLP syndrome 4 cases, HELLP syndrome with ARF in 2 case (2.8\%), Placental abruption in 3 cases $(4.2 \%)$, ARF in 3 cases $(4.32 \%)$, PRES in 2 cases $(2.8 \%)$ ), ARDS in 2 cases $(2.8 \%)$ and DIC in one case $(1.4 \%)$. There was 1 maternal mortality $(1.4 \%)$. In present series most of the cases were delivered by normal vaginal deliveries in $39.4 \%$ cases followed by caesarean section in $36.6 \%$ of cases.

Assisted vaginal deliveries include vacuum assistance in $21.1 \%$ of cases and forceps in $2.8 \%$ of cases. Except patients in renal failure, all others were treated magnesium sulphate according to Pritchard regimen. ${ }^{18}$ Those with renal failure received levitracetam. Patients with ARF underwent dialysis in 3 cases (4.2\%). Maternal mortality was $1.4 \%$. The patient who succumbed had eclampsia with ARDS. One patient of eclampsia with HELLP and ARF refused treatment and was lost to follow-up.

\section{CONCLUSION}

We conclude that severe preeclampsia and eclampsia are associated with higher rates of maternal severe morbidity, and these two still remain major contributors of maternal morbidity in Iran. Early and timely intervention is a very crucial life-saving factor.

\section{Funding: No funding sources} Conflict of interest: None declared

Ethical approval: The study was approved by the Institutional Ethics Committee

\section{REFERENCES}

1. Ngwenya S. Severe preeclampsia and eclampsia: incidence, complications, and perinatal outcomes at a low-resource setting, Mpilo Central Hospital, Bulawayo, Zimbabwe. Int J Women's Health. 2017;9:353-357.

2. Oyston CJ, Stanley JL, Baker PN. Potential targets for the treatment of preeclampsia. Expert Opin Ther Targets. 2015;19(11):1517-30.

3. Gathiram P, Moodley J. Pre-eclampsia: its pathogenesis and pathophysiology. Cardiovasc J Afr. 2016;27(2):71-8.

4. Say L, Chou D, Gemmill A, Tunçalp Ö, Moller AB, Daniels J, et al. Global causes of maternal death: a WHO systematic analysis. The Lancet Global Health. 2014;2(6):e323-33.

5. Ngwenya S. Postpartum haemorrhage: incidence, risk factors, and outcomes in a low resource setting. Int J Women's Health. 2016;8:647-50.

6. Nankali A, Malek-khosravi S, Zangeneh M, Rezaei M, Hemati Z, Kohzadi M. Maternal Complications Associated with Severe Preeclampsia. J Obstet Gynaecol India. 2013;63(2):112-5.

7. Hutcheon JA, Lisonkova S, Joseph KS. Epidemiology of pre-eclampsia and the other hypertensive disorders of pregnancy. Best practice and research Clinic Obstet Gynaecol. 2011;25(4):391-403.

8. Turner JA. Diagnosis and management of preeclampsia: an update. Int J Women's Health. 2010;2:327-37.

9. Zuberi NF, Arif K, Khan FM, Pal JA. A comparison of severe pre-eclampsia/eclampsia in patients with and without HELLP syndrome. J Pak Med Assoc. 1998;48(2):29-32.

10. Kinay T, Kucuk C, Kayikcioglu F, Karakaya J. Severe preeclampsia versus HELLP syndrome: maternal and perinatal outcomes at $<34$ and $\geq 34$ weeks' gestation. Balkan Med J. 2015;32(4):359363.

11. Ananth CV, Lavery JA, Friedman AM, Wapner RJ, Wright JD. Serious maternal complications in relation to severe pre-eclampsia: a retrospective cohort study of the impact of hospital volume. BJOG: Int J Obstet Gynaecol. 2017;124(8):1246-53.

12. WHO U. UNFPA, The World Bank and the United Nations Population Division. Trends in maternal mortality. 1990;2013:1-68.

13. Ghimire S. Eclampsia: feto-maternal outcomes in a tertiary care centre in Eastern Nepal. JNMA J Nepal Med Assoc. 2016;54(201):24-8.

14. Imarengiaye $\mathrm{CO}$, Isesele $\mathrm{TO}$. Intensive care management and outcome of women of women with hypertensive diseases of pregnancy. Niger Med J. 2015;56(5):333-7.

15. Paauw ND, Luijken K, Franx A, Verhaar MC, Lely AT. Long-term renal and cardiovascular risk after preeclampsia: towards screening and prevention. Clin Sci (Lond) 2016;130(4):239-246. 
16. Robillard PY, Dekker G, Iacobelli S, Chaouat G. An essay of reflection: Why does preeclampsia exist in humans, and why are there such huge geographical differences in epidemiology? J Reproduct Immunol. 2016;114:44-7.

17. Iacobelli S, Bonsante F, Robillard PY. Pre-eclampsia and preterm birth in Reunion Island: a 13 years cohort-based study. Comparison with international data. J Matern Fetal Neonatal Med. 2016;29(18):3035-40.

18. Duley L, Golmezoglu AM, Chou D. Magnesium sulphate versus lytic cocktail for eclampsia.
Cochrane Pregnancy and Childbirth Group. Cochrane Database Syst Rev. 2010;9:CD002960.

Cite this article as: Konnur H, Modi S. Maternal complications in eclampsia and pre-eclampsia: an institutional study. Int J Reprod Contracept Obstet Gynecol 2018;7:4992-5. 